\title{
Pre-clinical Stress Management Workshops Increase Medical Students' Knowledge and Self-awareness of Coping with Stress
}

\author{
Beryl Manning-Geist ${ }^{1}$ (D) Fremonta Meyer ${ }^{2} \cdot$ Justin $^{\text {Chen }}{ }^{2,3} \cdot$ Andrea Pelletier $^{1} \cdot$ Katherine Kosman $^{4}$. \\ Xiaodong (Phoenix) Chen ${ }^{1} \cdot$ Natasha R. Johnson ${ }^{1}$
}

Published online: 9 December 2019

(C) International Association of Medical Science Educators 2019

\begin{abstract}
Objectives To investigate the effects of a stress management workshop on medical students' knowledge of stress and potential coping strategies.

Methods A panel discussion with small group breakouts on stress in clinical medicine, learning challenges, competition with colleagues, handling stressful events, and recognizing burnout symptoms was conducted with medical students entering clerkships. A longitudinal survey design was utilized to measure pre-, post-, and long-term (3-month) changes in knowledge (impact of stress on personal health, learning, and patient care), confidence, perceived skills, and attitude (towards utilizing adaptive coping strategies) among participating students $(N=135)$. Paired $t$ test and multivariate analyses were performed to assess the differences between survey responses on a 5-point Likert scale.

Results Survey response rates were pre- $90.4 \%$, post-77\%, and long-term post- $71.1 \%$. Compared to pre-workshop, students reported significant improvement in all four domains immediately post-workshop: knowledge (4.4 vs. 4.7, $p<0.05$ ), confidence ( 3.6 vs. $3.9, p<0.05$ ), perceived skills ( 3.3 vs. $3.7, p<0.05$ ), and attitude ( 2.6 vs. $2.8, p<0.05$ ). Compared to immediate postworkshop, students' scores slightly decreased at 3 months but were overall significantly higher than the pre-workshop scores. Conclusions A stress management workshop can improve medical students' knowledge of the impact of stress as well as the use of adaptive stress coping strategies.
\end{abstract}

Keywords Medical students $\cdot$ Stress $\cdot$ Self-awareness $\cdot$ Coping strategies $\cdot$ Burnout

\section{Introduction}

Stress and burnout have been recognized as significant factors that influence medical trainees' aptitude [1], learning [2-5],

Beryl Manning-Geist

bmanning-geist@partners.org

1 Department of Obstetrics, Gynecology and Reproductive Biology, Brigham and Women's Hospital, Harvard Medical School, 75 Francis St., Boston, MA 02115, USA

2 Department of Psychiatry, Brigham and Women's Hospital, Harvard Medical School, Boston, MA, USA

3 Department of Psychiatry, Massachusetts General Hospital, Harvard Medical School, Boston, MA, USA

4 Department of Psychiatry, Beth Israel Deaconess Hospital, Harvard Medical School, Boston, MA, USA professionalism [6-9], wellness [9-12], and care of patients $[8,9,13]$. Stress is a psychological and physical process that occurs when a person is faced with a demand that is perceived to exceed the resources available to respond to it effectively $[14,15]$. Burnout is a state of mental and/or physical exhaustion caused by excessive and prolonged stress, and can be measured through the validated Maslach Burnout Inventory [14-17]. A recent study reported that at least half of all medical students might be affected by stress and burnout during medical school [17]. Dyrbye and colleagues revealed that the learning environment was significantly associated with medical student burnout; specifically, students rotating on hospital wards and those required to stay for overnight call were more likely to experience burnout [18]. Psychological distress can lead to depression and thus medical students are at high risk [19-22]. Compared with US college graduates age 22-32, medical students were more likely to exhibit symptoms of depression and had higher levels of fatigue [23]. Even more 
alarming is the recent finding that the prevalence of depression or depressive symptoms among medical students was $27.2 \%$ and that of suicidal ideation was $11.1 \%$ [24]. Thus, more attention needs to be paid to the stress phenomenon during undergraduate medical education, including students' awareness of stress and how to improve students' stress coping skills. This is particularly important during the challenging transition from the mostly didactic-filled pre-clerkship curriculum to patient-care focused clerkships which requires medical students to adjust to new learning environments, unpredictable schedules, and different expectations.

Studies have investigated interventions for students to minimize the stress inherent to medical education and training and to improve wellness $[25,26]$. Specifically, the effects of mindfulness-based stress reduction (MBSR) training on preclinical and clinical medical students have been shown to reduce depression [27, 28], anxiety [27], psychological distress $[27,29,30]$, perceived stress $[28,31,32]$, and emotional exhaustion [28] and to increase empathy [27], selfcompassion [28, 31], mindfulness skills [28, 30], positive mental health [30], life satisfaction [30], and spirituality [27]. Medical students, however, use various coping mechanisms that vary by year in training and source of the stress [33]. The specific coping strategies that students use may determine the effect of stress on their academic performance and well-being [14]. However, little is understood regarding medical students' knowledge of the impact of stress on their own health, learning, and patient care. In addition, there is a paucity of literature on medical students' knowledge of coping strategies available and self-awareness of the need to utilize adapting coping strategies to prevent burnout and depression [9]. Given the significant prevalence of psychological distress, burnout, and depression among medical students, it is critical for medical schools to equip students with the knowledge necessary to recognize stress, ability to determine when to seek assistance, and capacity to manage stress effectively to promote well-being and prevent burnout [9, 34, 35]. Therefore, we conducted a longitudinal survey study in medical students poised to initiate clinical clerkships in order to investigate the impact of a stress management workshop on knowledge and self-awareness of stress symptoms, impact of stress, and potential adaptive positive coping strategies.

\section{Materials and Methods}

\section{Setting and Participants}

A total of 135 medical students (representing one class year) were scheduled to participate in a stress management workshop at four academic hospitals affiliated with a single medical school prior to starting their clinical rotations as part of a larger Transition to the Principal Clinical Experience Course (transition to clinical clerkships course).

\section{Workshop Description}

The goals of the 2-h workshop were for students to (1) demonstrate increased knowledge of the negative impact of stress on their learning, personal health, and patient care; (2) recognize symptoms of stress; (3) demonstrate increased selfawareness of adaptive coping mechanisms to reduce stress and reduce the risk of burnout; and (4) identify the value of seeking help and available resources. The standardized workshop format consisted of a $1 \mathrm{~h}$ didactic on stress and burnout with specific emphasis on manifestations in clinical medicine including definitions, epidemiology, time trends, hypothesized contributors, recognition in self and others, management, and approaches. In addition, the didactic highlighted the importance of seeking help and resources available to students. The second hour consisted of a panel discussion and small group breakouts on topics of role confusion, power in the hospital, benefits/risks of empathy, competition with colleagues, conflicts with other medical professionals/patients, dealing with disappointment, pimping, challenges of learning, self-care, handling stressful events, facade of perfection, and work/life balance, as well as recognizing and managing symptoms of burnout. The curriculum content was derived from the literature, a previously conducted needs assessment, and expert opinion.

\section{Study Design}

Total population sampling was used to recruit student participants. A total of 135 medical students, representing one class year, were invited to attend a stress management workshop at their previously assigned academic hospital affiliated with a single medical school prior to starting clinical rotations. Participation in the study associated with the workshop was voluntary. Three surveys, including pre-workshop, immediate post-workshop, and a long-term (conducted 3 months after starting clinical rotations) post-workshop follow-up survey, were administered to the students. IRB approval was obtained from Partners and Harvard Medical School.

\section{Survey Instrument}

We utilized paper and pencil surveys for the pre- and immediate post-workshop surveys. The long-term post-workshop survey was distributed with the Qualtrics online survey tool, as students had started their clinical rotations in different hospitals. All surveys were anonymous and derived from validated instruments to measure students' knowledge of the negative impact of stress, symptoms of stress, utilization of positive coping strategies (derived 
from The Coping Strategies Inventory [36]), resources available, likelihood of utilizing resources, and current level of burnout, as assessed using the validated Maslach Burnout Inventory [16, 37]. The Maslach Burnout Inventory evaluates three aspects of perceived burnout including emotional exhaustion, depersonalization, and personal accomplishment [37]. The Maslach Burnout Inventory is widely used to assess burnout in a variety of settings, and has been extensively validated as a tool to assess perceived burnout in medical professionals [38]. Research team members reviewed and reached agreement on the final questions and construct of the survey instruments. Cognitive pretesting was conducted with four medical students to ensure that students would interpret the survey questions in the intended manner. All survey instruments included identical questions to measure students' perceived changes in stress management in four domains: knowledge (impact of stress on their own health, learning, and patient care), confidence, perceived skills, and attitude (towards utilizing adaptive coping strategies to prevent burnout), which used a 5-point Likert-type scale $(1=$ not at all, $5=$ extremely). Self-reported level of burnout (5point Likert-type scale; $1=$ completely burned out, $5=$ no symptoms of burnout) was assessed in the pre- and long-term post-workshop surveys. Ten questions (4-point Likert-type scale; $1=$ not at all, $4=$ a lot) about workshop satisfaction and helpfulness were also included in the postworkshop survey.

\section{Data Analysis}

Data were analyzed to determine the effects of the workshop on the study goals. Statistical analyses were conducted using JMP Pro statistical software (Version 12) as well as STATA (Version 15.0). Differences between pre- and immediate postworkshop responses were tested using paired $t$ tests to assess differences between continuous variables. A $p$ value of $<0.05$ was considered significant. Correlation coefficients were performed to measure the relationship between students' workshop satisfaction and their self-awareness of using positive stress coping techniques. We also calculated odds ratios to examine the association between students' reported level of burnout and other variables. Power analysis was not applicable as total population sampling was used and the survey response rate was reported.

\section{Results}

The overall survey response rate was $79.5 \%$ (pre-90.4\%, immediate post-77\%, 3-month post-workshop 71.1\%). In comparing combined ratings of 4 and 5 on the Likert scale ("quite a lot" and "extremely") on pre- to immediate post-workshop responses, students' knowledge of the impact of stress on their own health, learning, and patient care increased. However, this was not completely sustained by the 3-month post-workshop survey (conducted 3 months after starting clinical clerkships). Students' confidence and perceived skills towards utilizing adaptive coping strategies to handle stress (e.g., selfawareness) also improved from the pre- to immediate postworkshop, but also was not sustained by 3-month post-workshop. There was no change in attitude towards stress (seeking help is not a sign of weakness) over the 3 surveys. The trends examining impact of the workshop estimates over time (including pre-workshop, post-workshop, 3-month post-workshop) on the domains of knowledge, confidence, skills, and attitude are illustrated in Fig. 1.

Overall, students' mean survey responses demonstrated statistically significant improvement for knowledge about the impact of stress on their overall long-term success, health, learning and patient care, and confidence and skills in recognizing and utilizing adaptive strategies to handle stress and attitude towards seeking help increased from pre- to immediate post-workshop (T1 to T2) (see Table 1). The difference between survey responses within the four domains from preworkshop and 3-month post-workshop (T1 to T3) was not statistically significant, except for scores on recognizing symptoms of burnout and stress within the Confidence domain (see Table 1). However, the workshop was effective in increasing students' knowledge of where to find supporting resources if they feel stressed during their clinical rotations both at the medical school (64.5\% pre-workshop vs. $88.1 \%$ immediate post-workshop) and at their hospital site (18.2\% pre-workshop vs. $70 \%$ post-workshop).

The immediate post-workshop responses indicated that the majority of students enjoyed the workshop, learned the symptoms and impact of stress, and planned to use the knowledge of coping strategies gained from the workshop (Table 2). In addition, students found specific elements of the workshop to be overall helpful (improve wellness, know effects of stress, coping strategies, talking with peers). Hearing classmates' concerns about the clinical year was reported to be the most helpful element of the workshop (mean score $3.21, \mathrm{SD} \pm 0.92$ ) which occurred during the small group breakout section of the workshop. On long-term post-workshop surveying, students assigned a mean score of 2.21 (scale $1-5, \mathrm{SD} \pm 0.93$ ) to the question "Did the stress workshop help to improve selfawareness of using positive coping strategies during your clinical rotations?" We conducted Spearman correlation coefficient analysis and found a moderate positive correlation $(r$ ranged from 0.42 to $0.46, p<0.05$ ) between the following 5 items: satisfaction with the workshop, knowledge of stress symptoms, understanding of impact of stress, knowledge of coping strategies, and students' self-awareness of using adaptive stress coping strategies during clinical rotations in the future. 


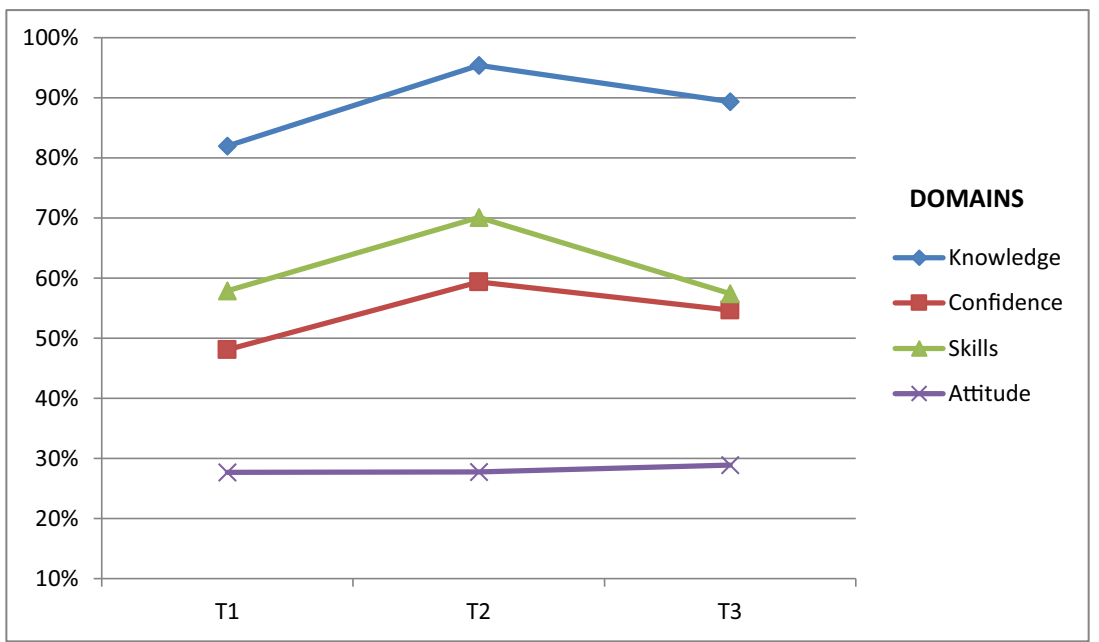

Fig. 1 Overall positive impact of the workshop estimates over time. Note: $\mathrm{T} 1=$ pre-workshop survey; $\mathrm{T} 2=$ post-workshop survey; $\mathrm{T} 3=3$ month post-workshop survey; all with 1-5 Likert scale; data have been re-coded; the higher rating, the better; the figure represents the overall percentage of combined ratings 4 ("quite a lot") and 5 ("extremely") reported by students over time; each percentage is the average of all survey questions under that given category. Domains: Knowledge of the impact of stress on students' own health, learning, and patient care. Confidence towards utilizing adaptive coping strategies in handling stress (e.g., self-awareness), perceived skills in addressing this stress, and attitude towards stress and seeking help (seeking help is not a sign of weakness)
Table 1 Mean and SD across 3 surveys

\begin{tabular}{|c|c|c|c|c|c|c|}
\hline$n=84$ & $\begin{array}{l}\text { T1 } \\
\text { Mean (SD) }\end{array}$ & $\begin{array}{l}\text { T2 } \\
\text { Mean (SD) }\end{array}$ & $p$ & $\begin{array}{l}\text { T1 } \\
\text { Mean (SD) } \\
n=65\end{array}$ & $\begin{array}{l}\text { T3 } \\
\text { Mean (SD) }\end{array}$ & $p$ \\
\hline \multicolumn{7}{|l|}{ Knowledge } \\
\hline Long-term success & $4.45(0.09)$ & $4.68(0.07)$ & $<0.01$ & $4.42(0.11)$ & $4.57(0.08)$ & 0.09 \\
\hline Health/wellness & $4.65(0.08)$ & $4.75(0.07)$ & 0.22 & $4.58(0.11)$ & $4.58(0.08)$ & 1.0 \\
\hline Learning & $4.36(0.10)$ & $4.63(0.08)$ & 0.003 & $4.26(0.11)$ & $4.38(0.10)$ & 0.22 \\
\hline Patient care & $4.48(0.09)$ & $4.63(0.07)$ & 0.04 & $4.40(0.11)$ & $4.43(0.10)$ & 0.71 \\
\hline Average & 4.49 & 4.67 & & 4.42 & 4.49 & \\
\hline \multicolumn{7}{|l|}{ Confidence } \\
\hline Recognize symptoms & $3.66(0.10)$ & $3.87(0.09)$ & 0.04 & $3.63(0.11)$ & $3.89(0.09)$ & 0.03 \\
\hline Identify sources* & $3.73(0.84)$ & $3.88(0.87)$ & 0.10 & $3.69(0.88)$ & $3.86(0.68)$ & 0.19 \\
\hline Activate positive emotion & $2.93(1.15)$ & $3.26(1.10)$ & 0.003 & $3.06(1.17)$ & $3.2(1.02)$ & 0.38 \\
\hline Reinterpretation & $2.94(1.16)$ & $3.15(1.06)$ & 0.07 & $3.11(1.13)$ & $3.28(1.04)$ & 0.30 \\
\hline Use self-distraction & $2.99(1.21)$ & $3.23(1.23)$ & 0.09 & $3.15(1.19)$ & $3.22(1.10)$ & 0.72 \\
\hline Share feeling & $3.29(1.22)$ & $3.60(1.12)$ & 0.01 & $3.39(1.16)$ & $3.28(1.07)$ & 0.50 \\
\hline Identify threats & $3.31(0.99)$ & $3.88(0.92)$ & $<0.001$ & $3.28(0.99)$ & $3.54(1.05)$ & 0.09 \\
\hline Recognize negative impact* & $3.83(0.97)$ & $4.06(0.96)$ & 0.03 & $3.97(0.93)$ & $3.94(1.0)$ & 0.84 \\
\hline Average & 3.34 & 3.62 & & 3.41 & 3.53 & \\
\hline \multicolumn{7}{|l|}{ Skills } \\
\hline New angle & $3.36(1.07)$ & $3.94(0.85)$ & $<0.001$ & $3.38(1.07)$ & $3.68(0.95)$ & 0.07 \\
\hline Problem takes care of itself & $3.66(1.05)$ & $3.69(1.04)$ & 0.78 & $3.48(1.00)$ & $3.46(0.89)$ & 0.91 \\
\hline Talk to someone & $3.52(1.17)$ & $3.73(1.13)$ & 0.14 & $3.60(1.17)$ & $3.48(1.17)$ & 0.43 \\
\hline Blame myself* & $3.27(1.12)$ & $3.75(0.91)$ & $<0.001$ & $3.34(1.06)$ & $3.28(0.92)$ & 0.68 \\
\hline Avoid being with people & $3.53(1.24)$ & $3.90(0.94)$ & 0.008 & $3.53(1.24)$ & $3.76(1.07)$ & 0.13 \\
\hline Avoid the person & $3.33(1.30)$ & $3.42(1.06)$ & 0.50 & $3.42(1.26)$ & $3.52(1.05)$ & 0.61 \\
\hline Solve the problem in situation & $3.48(0.94)$ & $4.01(0.86)$ & $<0.001$ & $3.54(0.94)$ & $3.60(1.01)$ & 0.66 \\
\hline Angry & $4.57(0.78)$ & $4.60(0.80)$ & 0.72 & $4.58(0.63)$ & $4.55(0.81)$ & 0.78 \\
\hline Average & 3.59 & 3.88 & & 3.61 & 3.67 & \\
\hline \multicolumn{7}{|l|}{ Attitude } \\
\hline Seeking help is a weakness & $2.62(1.28)$ & $2.89(1.15)$ & 0.05 & $2.71(1.26)$ & $2.75(1.21)$ & 0.80 \\
\hline
\end{tabular}

$\mathrm{T} 1$ = pre-workshop survey, T2 = immediate post-workshop survey, T3 = 3-month post-workshop survey; $S D$ standard deviation; all with 1-5 scale; data have been re-coded; the higher rating, the better. The mean differences between pre-workshop and immediate post- workshop were compared using paired $t$ tests. The mean differences between pre-workshop and 3-month post-workshop were also compared using paired $t$ tests. A $p$ value $<0.05$ was considered statistically significant 
Table 2 Satisfaction with workshop

\begin{tabular}{lll}
\hline Qs & Mean & Standard deviation \\
\hline Post-workshop satisfaction & & \\
Enjoy workshop & 3.30 & 0.82 \\
Learn symptoms of stress & 2.92 & 0.88 \\
Understand impact of stress & 2.86 & 0.93 \\
Knowledge of coping strategies & 3.00 & 0.83 \\
Use workshop knowledge & 3.23 & 0.76 \\
Post-workshop helpfulness & & \\
Helpful—improve wellness & 2.86 & 0.87 \\
Helpful - know effects of stress & 2.65 & 0.94 \\
Helpful—useful coping strategies & 2.97 & 0.83 \\
Helpful - talking w/peers & 2.86 & 1.01 \\
Helpful—-hear about peers' concerns & 3.21 & 0.92 \\
\hline
\end{tabular}

$Q$ questions, $S D$ standard deviation; all with 1-4 scale, 1 = "not at all," 2 "slightly," 3 = "moderately," 4 = "very"

Students were asked to rate their current level of burnout on the pre-workshop and 3-month post-workshop surveys (3 months after starting their clinical clerkships, scale 1-5; 1 $=$ completely burned out, $5=$ enjoy my work). There was a higher level of self-reported burnout at 3 months (mean 3.69 $\mathrm{SD} \pm 0.84$ ) compared to pre-workshop (mean $3.86 \mathrm{SD} \pm$ 0.83 ). We found no statistically significant relationship between students' self-reported burnout at 3 months and knowledge, confidence, perceived skill, or attitude scores. Students who disagreed that asking for help was a sign of weakness were statistically more likely to have self-reported burnout at 3-month post-workshop (OR 1.93, 95\% CI 1.13-3.28) (Table 3).

\section{Discussion}

Our study findings suggest that the 2-h stress management workshop had a positive impact on medical students' knowledge towards the symptoms and impact of stress as well as on their confidence, perceived skills, and attitude of using adaptive stress coping skills during their clinical rotations. Students' self-reported knowledge, confidence, and perceived skills increased immediately after the workshop; however, this improvement was largely not durable at the 3 -month postworkshop time point. It is possible that students' recall of the knowledge learned in the workshop was compromised by the high learning demands of clinical rotations. To prevent the knowledge decay, programs could incorporate a series of mindfulness-based stress training sessions [25-32] and accessible support in addition to a one-time stress management workshop to enhance students' knowledge retention and skill acquisition.

Results of the pre-workshop survey illustrate that students generally demonstrated a high level of knowledge about stress symptoms and their impact, followed by confidence and perceived skills to cope with stress, and attitude towards seeking help. These are consistent with the immediate post-workshop survey results about workshop satisfaction and helpfulness: students rated hearing their peers' concerns and learning useful stress coping strategies as the two most helpful educational contents of the workshop. These findings suggest that future stress management workshops should focus on introducing stress coping skills and provide a safe environment for students to share concerns and experiences.

Students' self-reported burnout increased by 3 months compared to pre-workshop levels (3 months after starting clinical clerkships) and did not correlate with their knowledge about
Table 3 Odds ratio between factors related to workshop and level of burnout (3 months)

\begin{tabular}{lllc}
\hline & OR & $95 \%$ CI & $p$ value \\
\hline Enjoy workshop & 1.10 & $0.53-2.30$ & 0.80 \\
Learn symptoms & 0.72 & $0.35-1.48$ & 0.36 \\
Understand impact & 0.70 & $0.35-1.41$ & 0.31 \\
Knowledge of coping & 1.00 & $0.51-1.96$ & 1.00 \\
Use workshop knowledge & 1.69 & $0.76-3.74$ & 0.19 \\
Content - improve wellness & 1.35 & $0.70-2.61$ & 0.37 \\
Content —effects of stress & 1.00 & $0.54-1.84$ & 1.00 \\
Content—coping strategies & 1.42 & $0.71-2.84$ & 0.31 \\
Content—-talking with peers & 0.94 & $0.50-1.77$ & 0.85 \\
Content - hearing peers' concerns & 0.86 & $0.42-1.75$ & 0.67 \\
Asking for help is a sign of weakness (3 months) & $1.93^{*}$ & $1.13-3.28$ & 0.008 \\
\hline
\end{tabular}

OR odds ratio; $\mathrm{OR}=1$, exposure does not affect odds of outcome; $\mathrm{OR}>1$, exposure associated with higher odds of outcome; OR $<1$, exposure associated with lower odds of outcome. Sign of weakness was re-coded $(5=$ strongly disagree asking for help is a sign of weakness); *only compared students who were matched across 3 surveys $(N=70)$ 
stress, confidence, or perceived skill in coping with stress. Burnout was correlated with students' attitude towards seeking help: students who were more open to seeking help were twice as likely report burnout at 3 months. This finding may be identifying premorbid depression, anxiety, or other mental health concerns; perhaps students who have already sought help in the past and are not opposed to reporting difficulty or seeking help in general. This highlights that it is critically important for students to know where to find resources should they need to seek help. Further, this finding may also reveal students who are empathetic and thus more likely to talk about their feelings and seek help. One theory is that a high level of empathy may cause "compassion fatigue" which then leads to emotional exhaustion and burnout [39]. Future studies are needed to further investigate the relationship between empathy and burnout among medical students, including whether increased screening for burnout should be used in students who are more likely to ask for help.

Our study has limitations, as previously described [40]. First, all participants are from a single medical school; results may therefore not be generalizable. Second, all survey results represent students' self-reported knowledge, confidence, perceived skills, and attitude, and do not measure actual performance or changes in behaviors. As these data are self-reported, there is an unavoidable potential for social desirability bias.

In conclusion, the stress management workshop had a positive impact on medical students' knowledge, confidence, perceived skills, and attitude of using adaptive stress coping strategies. Programs are encouraged to empower students to effectively self-manage stress and prevent burnout during clinical training by providing additional interventions after a stress management workshop to increase students' knowledge retention.

\section{Compliance with Ethical Standards}

Conflict of Interest The authors declare that there is no conflict of interest.

\section{References}

1. Hojat M, Gonnella JS, Mangione S, Nasca TJ, Veloski JJ, Erdmann $\mathrm{JB}$, et al. Empathy in medical students as related to academic performance, clinical competence and gender. Med Educ. 2002;36: 522-7.

2. Spiegel DA, Smolen RC, Hopfensperger KA. Medical student stress and clerkship performance. J Med Educ. 1986;61:929-31.

3. Hojat M, Robeson M, Damjanov I, Veloski JJ, Glaser K, Gonnella JS. Students' psychosocial characteristics as predictors of academic performance in medical school. Acad Med. 1993;68:635-7.

4. Chandavarkar U, Azzam A, Mathews CA. Anxiety symptoms and perceived performance in medical students. Depress Anxiety. 2007;24(2):103-11.

5. Sohail N. Stress and academic performance among medical students. J Coll Physicians Surg Pak. 2013;23(1):67-71.
6. Woloschuk W, Harasym PH, Temple W. Attitude change during medical school: a cohort study. Med Educ. 2004;38:522-34.

7. Hojat M, Mangione S, Nasca T, Rattner S, Erdmann JB, Gonnella JS, et al. An empirical study of decline in empathy in medical school. Med Educ. 2004;38:934-41.

8. Dyrbye LN, Massie FS Jr, Eacker A, et al. Relationship between burnout and professional conduct and attitudes among US medical students. JAMA. 2010;304:1173-80.

9. Dyrbye LN, Thomas MR, Shanafelt TD. Medical student distress: causes, consequences, and proposed solutions. Mayo Clin Proc. 2005;80(12):1613-22.

10. Ball S, Bax A. Self-care in medical education: effectiveness of health-habits interventions for first-year medical students. Acad Med. 2002;77:911-7.

11. Dyrbye LN, Thomas MR, Massie FS, Power DV, Eacker A, Harper W, et al. Burnout and suicidal ideation among U.S. medical students. Ann Intern Med. 2008;149:334-41.

12. Oreskovich MR, Kaups KL, Balch CM, et al. The prevalence of alcohol use disorders among American surgeons. Arch Surg. 2012;147:168-74.

13. West CP, Huschka MM, Novotny PJ, Sloan JA, Kolars JC, Habermann TM, et al. Association of perceived medical errors with resident distress and empathy: a prospective longitudinal study. JAMA. 2006;296:1071-8.

14. Fares J, Al Tabosh H, Saadeddin Z, El Mouhayyar C, Aridi H. Stress, burnout and coping strategies in preclinical medical students. N Am J Med Sci. 2016;8(2):75-81.

15. Hurd CL, Monaghan O, Patel MR, Phuoc V, Sapp JH. Medical student stress and burnout. Retrieved from: http://greenvillemed. sc.edu/doc/Medical\%20Student $\% 20$ Stress $\% 20$ and $\% 20$ Burnout $\%$ 20Feb\%202013.pdf. Accessed 1 May 2019.

16. Dolan ED, Mohr D, Lempa M, Joos S, Fihn SD, Nelson KM, et al. Using a single item to measure burnout in primary care staff: a psychometric evaluation. J Gen Intern Med. 2015;30(5):582-7.

17. IsHak W, Nikravesh R, Lederer S, Perry R, Ogunyemi D, Bernstein C. Burnout in medical students: a systematic review. Clin Teach. 2013;10:242-5.

18. Dyrbye LN, Thomas MR, Harper W, Massie FS Jr, Power DV, Eaker A, et al. The learning environment and medical student burnout: a multicentre study. Med Educ. 2009;43:274-82.

19. Rosal MC, Ockene IS, Ockene JK, Barrett SV, Ma Y, Hebert JR. A longitudinal study of students' depression at one medical school. Acad Med. 1997;72(6):542-6.

20. Dyrbye LN, Thomas MR, Shanafelt TD. Systematic review of depression, anxiety, and other indicators of psychological distress among U.S. and Canadian medical students. Acad Med. 2006;81(4):354-73.

21. Hope V, Henderson M. Medical student depression, anxiety and distress outside North America: a systematic review. Med Educ. 2014;48(10):963-79.

22. Brazeau CM, Shanafelt T, Durning SJ, Massie FS, Eacker A, Moutier C, et al. Distress among matriculating medical students relative to the general population. Acad Med. 2014;89(11):1520-5.

23. Dyrbye LN, West CP, Satele D, Boone S, Tan L, Sloan J, et al. Burnout among U.S. medical students, residents, and early career physicians relative to the general U.S. population. Acad Med. 2014;89(3):443-51.

24. Rotenstein LS, Ramos MA, Torre M, Segal JB, Peluso MJ, Guille $\mathrm{C}$, et al. Prevalence of depression, depressive symptoms, and suicidal ideation among medical students: a systematic review and meta-analysis. JAMA. 2016;316(21):2214-36.

25. Pereira MA, Barbosa MA, Rezende JC, Damiano RF. Medical student stress: an elective course as a possibility of help. BMC Res Notes. 2015;8:430. 
26. Chen AK, Kumar A, Haramati A. The effect of mind body medicine course on medical student empathy: a pilot study. Med Educ Online. 2016;21:31196.

27. Shapiro SL, Schwartz GE, Bonner G. Effects of mindfulness-based stress reduction on medical and premedical students. J Behav Med. 1998;21:581-99.

28. Garneau K, Hutchinson T, Zhao Q, Dobkin P. Cultivating personcentered medicine in future physicians. Eur J Pers Cent Healthc. 2013;1:468-77.

29. Rosenzweig S, Reibel DK, Greeson JM, Brainard GC, Hojat M. Mindfulness-based stress reduction lowers psychological distress in medical students. Teach Learn Med. 2003;15:88-92.

30. Van Dijk I, Lucassen P, Akkermans R, van Engelen B, van Weel C, Speckens A. Effects of mindfulness-based stress reduction on the mental health of clinical clerkship students: a cluster-randomized controlled trial. Acad Med. 2017.

31. Erogul M, Singer G, McIntyre T, Stefanov DG. Abridged mindfulness intervention to support wellness in first-year medical students. Teach Learn Med. 2014;26:350-6.

32. Warnecke E, Quinn S, Ogden K, Towle N, Nelson MR. A randomised controlled trial of the effects of mindfulness practice on medical student stress levels. Med Educ. 2011;45:381-8.

33. Stern M, Norman S, Komm C. Medical students' differential use of coping strategies as a function of stressor type, year of training, and gender. Behav Med. 1993 Winter;18(4):173-80.
34. Howe A, Smajdor A, Stöckl A. Towards and understanding of resilience and its relevance to medical training. Med Educ. 2012;46(4):349-56.

35. Novack DH, Epstein RM, Paulsen RH. Toward creating physician healers: fostering medical students self-awarenss, personal growth, and well being. Acad Med. 1999;74(5):516-20.

36. Tobin DL. Use manual for the coping strategies inventory. Retrieved from: http://docplayer.net/9504132-User-manual-forthe-coping-strategies-inventory.html. Accessed 1 May 2019.

37. Maslach C, Jackson S, Leiter M. Maslach burnout inventory manual. 3rd ed. Palo Alto: Consulting Psychologists Press; 1996.

38. Rafferty JP, Lemkau JP, Purdy RR, Rudisill JR. Validity of the Maslach burnout inventory for family practice physicians. Clin Psychol. 1986;42(3):488-92.

39. Zenasni F, Boujut E, Woerner A, Sultan S. Burnout and empathy in primary care: three hypotheses. Br J Gen Pract. 2012;62(600):3467.

40. Johnson NR, Pelletier A, Chen X, Manning-Geist BL. Learning in a high-stress clinical environment: stressors associated with medical students' clerkship training on labor and delivery. Teach Learn Med. 2019;25:1-8.

Publisher's Note Springer Nature remains neutral with regard to jurisdictional claims in published maps and institutional affiliations. 